\title{
Training in Neurology: Implementation and Evaluation of an Objective Structured Clinical-Examination Tool for Neurology Postgraduate Trainees in Lusaka, Zambia
}

Rebecca Marie DiBiase, MD, MPH, Rachel Marie E. Salas, MD, MEd, Charlene E. Gamaldo, MD, Aparna Nutakki, BA, Isabel Elicer, MD, Hrayr P. Attarian, MD, Kenneth C. Kapembwa, MD, Roy E. Strowd, MD, MEd, Sean Tackett, MD, MPH, and Deanna R. Saylor, MD, MHS

Neurology ${ }^{\circledR}$ 2021;97:e750-e754. doi:10.1212/WNL.0000000000012134

\section{Abstract}

\section{Background}

We established Zambia's first neurology residency program at the University of Zambia School of Medicine and the University Teaching Hospital in Lusaka.

\section{Objective}

To evaluate the feasibility and effectiveness of a modified objective structured clinical examination (OSCE) to assess clinical skills.

\section{Methods}

The neurology training program's 3 participants completed the OSCE exercise in February 2019. We used smartphones to videotape trainees performing a physical examination and oral presentation in the neurology clinic. Trainees and faculty reviewed the videos independently using a standardized rubric and then met for in-person feedback.

\section{Results}

Three trainees completed pre- and post-OSCE surveys rating their confidence in elements of the history and examination. Trainees' average self-confidence scores improved from the pre- to post-OSCE survey in every category (pre-OSCE: mean score 6.84, range 4.8-7.8, SD 0.92; post-OSCE: mean score 7.9, range 5.67-9.33, SD 0.86). Qualitative feedback showed trainees found the OSCE helpful, routinely applied feedback, and would appreciate repeating OSCEs.

\section{Conclusions}

OSCEs improve trainees' self-confidence and can be modified and successfully implemented in a resource-limited neurology postgraduate training program. Important OSCE modifications involved using smartphones for videotaping and a real patient encounter rather than a standardized patient. Embedding the experience within a busy clinic day was practical, applicable, and efficient. Future work should expand use of OSCEs both within the Zambian neurology residency program and non-neurology training programs. Including additional video reviewers could add to the validity of clinical skills assessment. Videos could also be used for remote mentorship and teaching purposes.
Correspondence

Dr. DiBiase

rebecca.dibiase@

northwestern.edu

From the Department of Neurology (R.M.D., H.P.A.), McGaw Medical Center of Northwestern University, Chicago, IL; Department of Neurology (R.M.E.S., C.E.G., R.E.S., D.R.S.), Johns Hopkins School of Medicine, Baltimore, MD; Rush Medical College at Rush University (A.N.), Chicago, IL; Hospital Dr. Sótero del Rio (I.E.), Red Salud UC Christus, Clinica Las Condes, Santiago, Chile; University Teaching Hospital (K.C.K., D.R.S.), Lusaka, Zambia; Department of Neurology, Wake Forest School of Medicine (R.E.S.), Winston-Salem, NC; and Department of Internal Medicine (S.T.), Johns Hopkins Bayview Medical Center, Baltimore, MD.

Go to Neurology.org/N for full disclosures. Funding information and disclosures deemed relevant by the authors, if any, are provided at the end of the article. 


\section{Glossary}

OSCE $=$ Objective Structured Clinical Examination.

Zambia is a lower-middle income country in sub-Saharan Africa ${ }^{1}$ with few neurologists despite its high burden of neurologic disease. Top 10 mortality causes include HIV/AIDS, malaria, stroke, meningitis, syphilis, and road traffic accidents, ${ }^{2,3}$ all either primary neurologic conditions or with frequent neurologic complications. Prior to 2018, only 4 neurologists were available in Zambia, all expatriates in the capital city. ${ }^{4}$ The first postgraduate neurology training program was started in October 2018 at the University of Zambia School of Medicine and University Teaching Hospital with support from the Zambian Ministry of Health.

This program offers the opportunity to develop and evaluate an evidence-based curriculum in a novel setting with high patient volume but limited resources. Trainees' selfconfidence and clinical growth must be fostered in an efficient, economical manner that does not compromise patient time and care. Valid clinical skills assessments create credibility for a new program and its graduates and develop momentum for the growing Zambian neurology workforce.

The Objective Structured Clinical Examination (OSCE) is a widely used method for clinical skills assessment. We describe the implementation of an adapted OSCE model to our local context and use self-confidence scores and qualitative feedback to assess its feasibility and utility in an environment with limited resources, space, and funding.

\section{Program Description}

The 2-year neurology postgraduate training program at the University of Zambia School of Medicine enrolls physicians after 3 years of internal medicine postgraduate training. The program incorporates clinical training on inpatient services with an average census of $30-50$ patients and weekly outpatient clinics in which trainees typically see $10-15$ patients each. In addition, trainees have 8-10 hours weekly of didactic sessions, including traditional lectures, journal clubs, research methods seminars, and case conferences. Supported by the Ministry of Health and a Fulbright fellowship, the program was developed and is directed by Dr. Deanna Saylor, a Johns Hopkins faculty neurologist.

The OSCE exercise was implemented for the program's 3 postgraduate trainees during their fifth month of clinical neurology training to allow time to obtain institutional support and adequately plan for curriculum implementation.

One day prior to the OSCE, trainees completed a survey (data available from dryad [supplemental materials, doi.org/10. 5061/dryad.2jm63xsnc]) requiring them to rank their perceived competency in establishing therapeutic relationships, eliciting comprehensive histories, performing the neurologic examination correctly and efficiently, localizing lesions, giving oral presentations, ordering appropriate diagnostic tests, and formulating care plans. They were then videotaped performing a neurologic examination and giving an oral presentation in the outpatient neurology clinic. Real patients were used in lieu of standardized patients. Trainees chose which patient encounter was videotaped, provided it was a new patient who consented to participation. New patient encounters were used to mitigate potential bias if trainees knew return patients. Given that the exercise was formative and trainees were independent adult learners, we allowed them to choose the patient encounter.

Videos were made using smartphones and immediately downloaded to a password-protected file only accessible by trainees and faculty. Within 48 hours of their clinical encounter, trainees reviewed their videos and rated themselves on their examination and presentation skills using a rubric with the same elements as the pre-OSCE survey (data available from Dryad [supplemental materials, doi.org/10.5061/dryad.2jm63xsnc]). A supervising faculty member also independently reviewed videos and completed the same rubric. The faculty member and trainee then shared and discussed their assessments to identify strengths and areas for improvement within 1 week of the patient encounter. Discussions took place in person or via telephone. OSCE videos were then deleted. Trainees completed a post-OSCE survey (data available from Dryad [supplemental materials, doi.org/10.5061/dryad.2jm63xsnc]) within 1 week of their faculty feedback session, and changes from pre-OSCE surveys were calculated. They also provided qualitative questionnaire feedback (data available from Dryad [supplemental materials, doi.org/10.5061/dryad.2jm63xsnc]) about the OSCE. The study was approved by the Johns Hopkins Institutional Review Board, the University of Zambia Biomedical Research Ethics Council, and the Zambia National Health Research Authority.

\section{Assessment and Outcomes}

Three postgraduate neurology trainees and 2 faculty members participated, which required 2-3 hours for trainees and 1 for faculty. This study had no associated costs, as we used personal smartphones, free Qualtrics survey software, and electronic rubrics.

The mean survey self-confidence scores increased in all categories (figure) post-OSCE, with most improvement in performing the parietal, motor, and sensory examinations. Average self-confidence improved from pre-OSCE to post- 


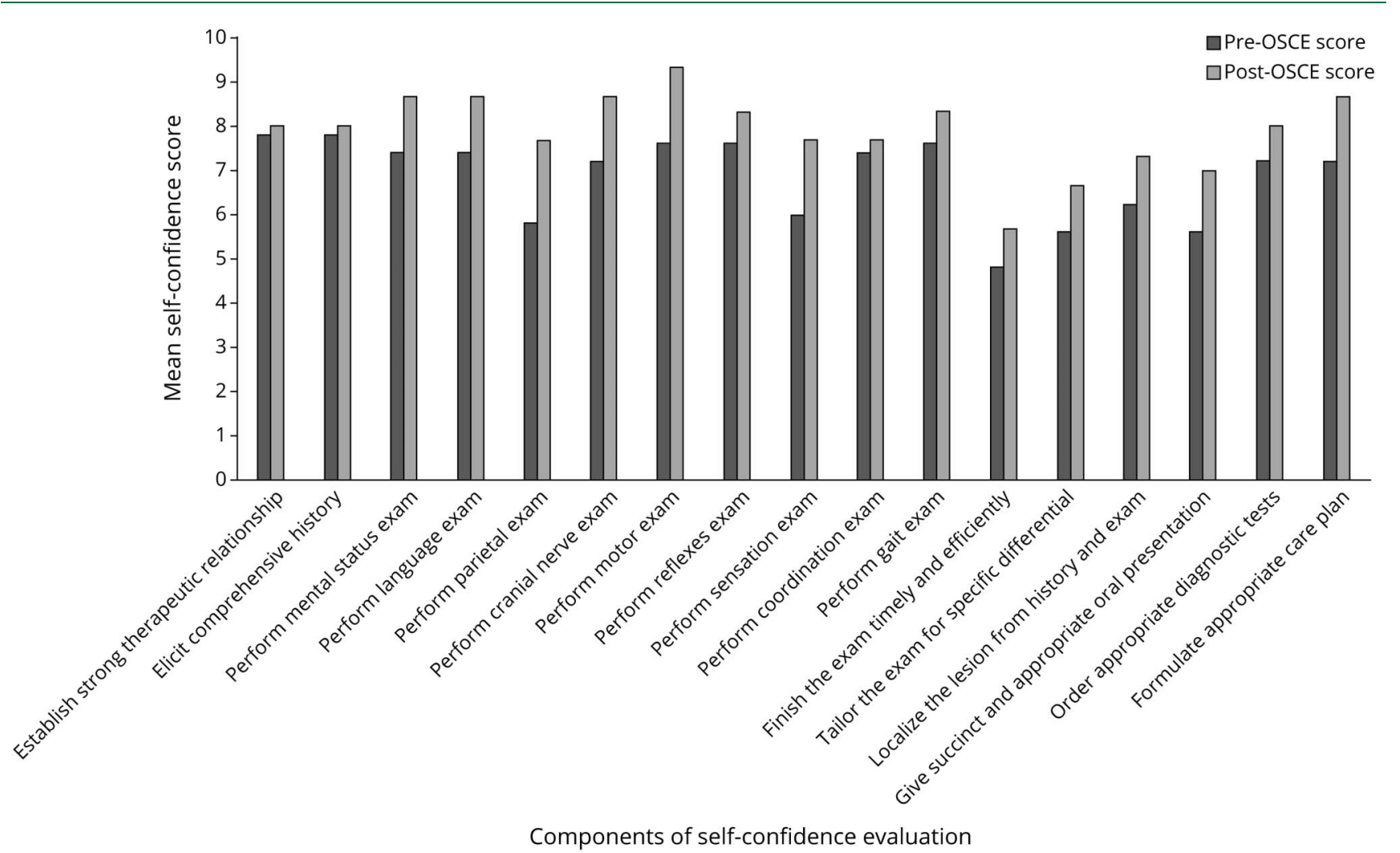

Data were gathered using pre- and postintervention questionnaires. Alhough $\mathrm{n}=3$ is too limited for $t$ test and $p$ value evaluations, graphical change trends in self-confidence are depicted. OSCE = Objective Structured Clinical Examination.

OSCE (pre-OSCE: mean score 6.84, range 4.8-7.8, SD 0.92; post-OSCE: mean score 7.9, range 5.67-9.33, SD 0.86). All trainees reported applying OSCE feedback in everyday clinical practice, endorsed it would "probably" or "definitely" be helpful to have periodic OSCEs, and suggested repeating the examination portion "every few months" $(\mathrm{n}=2)$ or "every 6 months" $(\mathrm{n}=1)$, and the oral presentation portion "more than once a month" $(\mathrm{n}=1)$ or "every few months" $(\mathrm{n}=2)$.

In open-ended feedback, comments included the following:

\footnotetext{
"It was helpful to see the gaps in my presentation and helped me realize how less succinct it was."

"Great idea to have frequent OSCE practice by video. Either in-person or video feedback is very helpful."

"It was useful in the sense that I could review faculty feedback while watching the video and I could repeatedly review my errors and good techniques [in] history presentation and examination."

"It helps to self-assess, and with feedback from the observer, I have in visual form the changes I need to make."
}

Future suggestions included videotaping oral presentations during case conferences, telephone presentations to a consultant, and taping when trainees were unaware they were being taped.

\section{Lessons Learned}

Preliminary data showed the OSCE improved trainees' selfconfidence in their clinical practice, was perceived as useful, and was worth repeating. Confidence in evaluating and managing patients is particularly important in the demanding Zambian medical environment, where high clinical demand requires trainees to adopt autonomy, adaptability, and leadership early. The OSCE provides a unique window for trainees to develop their skills, self-assess, and build selfassurance.

Our study is innovative in its inclusion of the oral presentation, an essential clinical communication skill. This modification to the conventional OSCE, which often includes only the history and physical examination, was viewed favorably among trainees. Our modifications, including using smartphones, capturing trainees in a clinic environment, and using real rather than standardized patients, enabled feasibility in a resource-limited setting. Effective OSCE curricula have been implemented in medical schools in Argentina and Pakistan using volunteer actors and faculty members as standardized patients and a learning space set apart from the clinical environment. ${ }^{5,6}$ However, our study is the first reported adapted OSCE in a postgraduate training program. OSCE integration in an authentic clinical environment 
incorporates aspects of the Clinical Evaluation Exercise (CEX), another medical education tool with formative benefits for medical trainees. ${ }^{7}$ Our modified OSCE utilizes the same concept of capturing trainees in a clinical environment, but with the OSCE's heightened rigor and more standardized and substantive feedback.

\section{Future Directions}

We implemented the curriculum within a small postgraduate program of 3 trainees, and thus statistical rigor of the reported outcomes was limited. In the future, we hope to implement multiple OSCE exercises and evaluate trends in self-confidence over time while recognizing they will be influenced by other factors, including increasing clinical experience. We are working to adapt the exercise to the Zambian pediatric neurology postgraduate training program. Future application will require ongoing trainee and faculty investment, which may be challenging given time-consuming clinical requirements. However, we have integrated OSCEs within a clinic schedule to minimize extra time spent and maximize opportunities for formative feedback.

We also hope to diversify the patient encounters and clinical settings captured, implement trainees' suggestions to incorporate clinical consult and case conference presentations, and add peer and patient feedback. While not reported here due to concerns for learner confidentiality, our study included objective outcome measures in the form of a score on a standardized assessment rubric (data available from Dryad [supplemental materials, doi.org/10.5061/dryad.2jm63xsnc]), and analyzing scores over time will help gauge objective programmatic success.

Our training program is supported by visiting volunteer faculty spending 2-4 weeks in Zambia, which makes educator continuity difficult. However, this provides opportunity for a wider range of faculty feedback. Validation of the rubric's interrater reliability is needed. OSCE videos may also be helpful as educational teaching demonstrations to highlight trainee variability and appropriate feedback methods.

In the travel-limited climate of the severe acute respiratory syndrome coronavirus 2 (SARS-CoV-2) pandemic, one valuable aspect of the OSCE videos is their ability to be used remotely for distance learning. The videotaped OSCE may be a helpful tool to support international training programs. However, inadequate Internet bandwidth and means for secure video exchange may limit implementation.

To expand the findings of our study, we hope to investigate whether this OSCE format has similar effects on increasing self-confidence in clinical neurology skills among trainees in non-neurologic specialties. If so, OSCEs may help reduce "neurophobia" among other clinicians. We hope to repeat this study with undergraduate medical students, for whom changes in self-confidence can have a profound effect on future career specialty choices, in turn helping to expand the pipeline of future Zambian neurologists. Finally, lessons learned from our program can be utilized for educational endeavors in other settings with similar resource constraints.

\section{Study Funding}

The authors report no targeted funding.

\section{Disclosure}

The authors have no relevant disclosures to report. Go to Neurology.org/N for full disclosures.

\begin{tabular}{|c|c|c|}
\hline Name & Location & Contribution \\
\hline $\begin{array}{l}\text { Rebecca } \\
\text { Marie } \\
\text { DiBiase, MD, } \\
\text { MPH }\end{array}$ & $\begin{array}{l}\text { Northwestern University, } \\
\text { Chicago, IL }\end{array}$ & $\begin{array}{l}\text { Study design, major role in } \\
\text { data collection, drafted the } \\
\text { manuscript }\end{array}$ \\
\hline $\begin{array}{l}\text { Rachael } \\
\text { Marie E. } \\
\text { Salas, MD, } \\
\text { MEd }\end{array}$ & $\begin{array}{l}\text { Johns Hopkins University } \\
\text { School of Medicine, } \\
\text { Baltimore, MD }\end{array}$ & $\begin{array}{l}\text { Study design, revised the } \\
\text { manuscript for intellectual } \\
\text { content }\end{array}$ \\
\hline $\begin{array}{l}\text { Charlene E. } \\
\text { Gamaldo, MD }\end{array}$ & $\begin{array}{l}\text { Johns Hopkins University } \\
\text { School of Medicine, } \\
\text { Baltimore, MD }\end{array}$ & $\begin{array}{l}\text { Study design, revised the } \\
\text { manuscript for intellectual } \\
\text { content }\end{array}$ \\
\hline $\begin{array}{l}\text { Aparna } \\
\text { Nutakki, BA }\end{array}$ & Rush University, Chicago, IL & $\begin{array}{l}\text { Major role in data } \\
\text { collection, revised } \\
\text { manuscript for intellectual } \\
\text { content }\end{array}$ \\
\hline $\begin{array}{l}\text { Isabel Elicer, } \\
\text { MD }\end{array}$ & $\begin{array}{l}\text { Hospital Dr Sotero del Rio, } \\
\text { Santiago, Chile }\end{array}$ & $\begin{array}{l}\text { Major role in data } \\
\text { collection, revised the } \\
\text { manuscript for intellectual } \\
\text { content }\end{array}$ \\
\hline $\begin{array}{l}\text { Hrayr P. } \\
\text { Attarian, MD }\end{array}$ & $\begin{array}{l}\text { Northwestern University, } \\
\text { Chicago, IL }\end{array}$ & $\begin{array}{l}\text { Major role in data } \\
\text { collection, revised the } \\
\text { manuscript for intellectual } \\
\text { content }\end{array}$ \\
\hline $\begin{array}{l}\text { Kenneth C. } \\
\text { Kapembwa, } \\
\text { MD }\end{array}$ & $\begin{array}{l}\text { University Teaching Hospital, } \\
\text { Lusaka, Zambia }\end{array}$ & $\begin{array}{l}\text { Revised the manuscript for } \\
\text { intellectual content }\end{array}$ \\
\hline $\begin{array}{l}\text { Roy E. } \\
\text { Strowd, MD, } \\
\text { MEd }\end{array}$ & $\begin{array}{l}\text { Wake Forest School of } \\
\text { Medicine, Winston-Salem, } \\
\text { NC; Johns Hopkins University } \\
\text { School of Medicine, } \\
\text { Baltimore, MD }\end{array}$ & $\begin{array}{l}\text { Revised the manuscript for } \\
\text { intellectual content }\end{array}$ \\
\hline
\end{tabular}

Sean Tackett Johns Hopkins University Revised the manuscript for

Sean Tackett, Johns Hopkins University Revised the manuscript for MD, MPH School of Medicine, intellectual content Baltimore, MD

\begin{tabular}{lll}
\hline Deanna R. & University Teaching Hospital, & Major role in data \\
Saylor, MD, & Lusaka, Zambia; Johns & collection, study design, \\
MHS & $\begin{array}{l}\text { Hopkins University School of } \\
\text { revised the manuscript for }\end{array}$ & $\begin{array}{l}\text { redicine, Baltimore, MD } \\
\text { intellectual content }\end{array}$
\end{tabular}

\section{References}

1. The World Bank, The World Bank Group. Zambia, 2019 data. Accessed May 12, 2020. https://www.worldbank.org/en/country/zambia

2. Centers for Disease Control and Prevention. CDC in Zambia. Accessed May 9, 2021. cdc.gov/globalhealth/countries/zambia/

3. Siddiqi O. Developing neurological care in Zambia. In: Center BIDM, ed. 2015. unaids.org/en/regionscountries/countries/zambia. 
4. Bergen DC, Good D. Neurology training programs worldwide: a World Federation of Neurology survey. J Neurol Sci. 2006;246(1-2):59-64.

5. Vargas AL, Boulet JR, Errichetti A, van Zanten M, López MJ, Reta AM. Developing performance-based medical school assessment programs in resource-limited environments. Med Teach. 2007;29(2-3):192-198.
6. Igbal M, Khizar B. Revising an objective structured clinical examination in a resourcelimited Pakistani Medical School. Educ Health. 2009;33(1):209.

7. Pelgrim EA, Kramer AW, Mokkink HG, van den Elsen L, Grol RP, van der Vleuten CP. In-training assessment using direct observation of single-patient encounters: a literature review. Adv Health Sci Educ Theor Pract. 2011;16(1-2):131-142. 


\section{Neurology}

Training in Neurology: Implementation and Evaluation of an Objective Structured Clinical-Examination Tool for Neurology Postgraduate Trainees in Lusaka, Zambia Rebecca Marie DiBiase, Rachel Marie E. Salas, Charlene E. Gamaldo, et al. Neurology 2021;97;e750-e754 Published Online before print April 30, 2021

DOI 10.1212/WNL.0000000000012134

This information is current as of April 30, 2021

Updated Information \& Services

References

Subspecialty Collections

Permissions \& Licensing

Reprints including high resolution figures, can be found at: http://n.neurology.org/content/97/7/e750.full

This article cites 4 articles, 0 of which you can access for free at: http://n.neurology.org/content/97/7/e750.full\#ref-list-1

This article, along with others on similar topics, appears in the following collection(s):

All Education

http://n.neurology.org/cgi/collection/all_education All global neurology

http://n.neurology.org/cgi/collection/all_global_neurology

Methods of education

http://n.neurology.org/cgi/collection/methods_of_education

Training-international

http://n.neurology.org/cgi/collection/training_international

Underserved populations

http://n.neurology.org/cgi/collection/underserved_populations

Information about reproducing this article in parts (figures,tables) or in its entirety can be found online at:

http://www.neurology.org/about/about_the_journal\#permissions

Information about ordering reprints can be found online:

http://n.neurology.org/subscribers/advertise

Neurology ${ }^{\circledR}$ is the official journal of the American Academy of Neurology. Published continuously since 1951, it is now a weekly with 48 issues per year. Copyright (C 2021 American Academy of Neurology. All rights reserved. Print ISSN: 0028-3878. Online ISSN: 1526-632X.

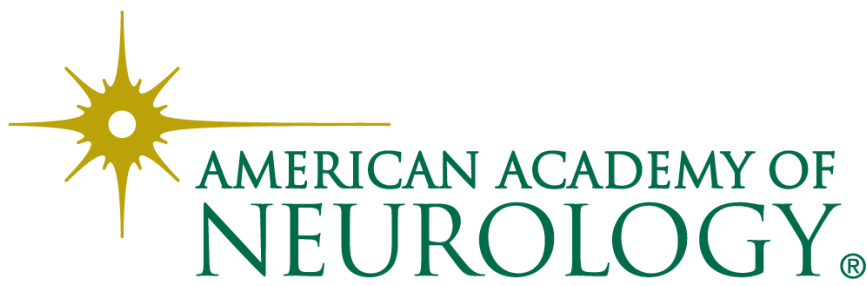

